


\section{Cambio climático: el drama de la información}

Uno de los comentarios que suele escucharse entre los intelectuales, cada vez que alguien - y las ocasiones son verdaderamente escasas - intenta discutir sobre los noticieros de televisión es: los medios son intolerablemente sensacionalistas. Por supuesto, se trata de aquellas circunstancias en las que algunos aprovechan para sacar una de esas palabras sofisticadas (no se puede negar la elegancia del término sensacionalista) y, con un gesto despectivo, propio de quien parece ha reflexionado demasiado sobre el asunto, gozar de las delicias de la erudición. En ese momento la discusión termina, acaso porque el tema sea en sí mismo despreciable - parece que ya se sabe todo acerca de los noticieros de nuestro país, parece que sólo basta con decir que son una empresa de la oligarquía - o porque nada puede reprochársele a la belleza de la palabra sensacionalista.

Se plantearán aquí algunos de los resultados del análisis del discurso de las noticias de $\mathrm{RCN}$, en el horario Triple A, realizado entre el 16 de agosto y el 16 de septiembre de 2011, que se ocupan del tema del cambio climático. La hipótesis con la que se inició la investigación era sencilla: las noticias son sensacionalistas; después de algunas reflexiones, comprendí muy bien lo que me proponía: quería demostrar los modos por los cuales un discurso llega a ser sensacionalista, y revelar las características de estos discursos.

Se estudiaron las informaciones del telenoticiero de RCN, los supuestos a partir de los cuales se construye la noticia y los rasgos propios de la información de los noticieros en televisión. Así, el análisis de las noticias es un análisis crítico de discurso, para este caso audiovisual, con el que se determinaron las características de la construcción de las noticias y los sentidos que entrañan.

\section{El método}

\section{La observación tiene un espacio y un tiempo}

Las noticias sobre el cambio climático en el noticiero estudiado se observaron con especial atención desde hace alrededor de dos años. Se tiene un registro de grabaciones de aproximadamente seis meses. Sin embargo, para llevar a cabo el análisis, se seleccionó el material emitido por Noticias RCN entre el 16 de agosto de 2011 y el 16 de septiembre de 2011. Se consideró como criterio esta temporalidad por ser inmediatamente anterior a lo que se ha denominado "la llegada de la ola invernal". Este criterio está justificado por la previa observación de las noticias, pues se determinó que una vez el tema de la temporada de lluvias empezó a ser parte de la agenda del telenoticiero, hubo un incremento notorio de las noticias sobre cambio climático. 


\section{Las formas de invisibilización. Violencia simbólica}

Opté por no incluir en los resultados de la investigación ni en el presente artículo la ya conocida discusión acerca de las condiciones políticas y económicas en las cuales se elabora la información televisiva. Evitar la descripción minuciosa de las formas en las que el sistema económico-político dentro del que se ubica el objeto de mi estudio influye en la construcción de los discursos informativos acerca del medio ambiente, no ha sido una alternativa que pretenda evadir las dificultades de este estudio. Tal decisión se debe a la convicción de que un estudio de tal índole, además de haberse convertido en casi un lugar común entre los investigadores del discurso noticioso, no explica plenamente el fenómeno, en tanto parece arrojar una tácita justificación sobre las licencias que los periodistas (y directores de medios) se dan por la coerción de las estructuras económicas y en tanto “ocultan los mecanismos anónimos, invisibles, a través de los cuales se ejercen censuras de todo orden que hacen que la televisión sea un colosal instrumento de mantenimiento del orden simbólico" (Bourdieu, 1997:20).

Quiero ocuparme de lo que Bourdieu ha llamado ocultar mostrando para hacer algunas observaciones acerca de las formas en las que se invisibilizan los aspectos verdaderamente relevantes de la noticia. Se trata ante todo de un mecanismo por el cual se privilegian ciertos aspectos de la información, aquellos que económica y políticamente son más rentables, en detrimento de aquellos que tienen una verdadera importancia, en tanto dotan a las personas de conocimientos necesarios para el ejercicio de sus derechos y deberes democráticos.

Como se ha visto, las categorías de percepción descubiertas en los discursos estudiados en esta investigación dan mayor relevancia al aspecto dramático y negativo de la noticia. No se trata de una invisibilización que se manifiesta por la no presentación de los acontecimientos relativos al cambio climático. Se trata de una forma de ocultar bastante sutil en la cual se presentan las consecuencias más obvias de los fenómenos estudiados desde el punto de vista más elemental posible, el sensacionalista. Sobre cada uno de los fenómenos noticiados, sobre cada una de sus singularidades, se opera una reducción y un empobrecimiento de su sentido así como una homogeneización de la información. Visto desde la perspectiva de Bourdieu, el acto comunicativo no se realiza, ya que de cada noticia se está afirmando esencialmente lo mismo, de modo que aquello que el emisor dice ya es conocido por el receptor. (He dicho afirmando exactamente porque no puedo utilizar el término cuestionando). Las consecuencias son nefastas. En un sentido, se manifiestan en el desconocimiento, por parte de los medios y de los consumidores, de los diferentes campos en los cuales el tema estudiado se inmiscuye. En otro sentido, que no es completamente independiente, debilita la capacidad de la acción colectiva, pues lo único que se le ofrece al espectador es un terror incierto por los acontecimientos. Se ejecuta entonces una forma de violencia simbólica en dos órdenes, el del pensamiento-reflexión y el de la acción civil.

A través del discurso se ejerce una dominación sobre un grupo social o diversos grupos sociales, por otro u otros grupos; tal dominación se inicia en las mentes de los consumidores de los discursos y desemboca en la dominación simbólica de los pensamientos, concepciones y conductas de los individuos. Este proceso de dominación discursiva puede definirse, para usar una noción de Bourdieu, como violencia simbólica que, según el francés, es un tipo de violencia cuasi invisible que opera en el orden abstracto y que sólo puede funcionar apoyándose en una estructura cognitiva que no es conocida pero que hace parte de las modalidades del pensamiento de quien sufre el acto de violencia. Se trata fundamentalmente de las formas de pensamiento, y por tanto de acción que, culturalmente, de acuerdo a ciertas jerarquizaciones sociales, se imponen sobre los individuos. Así, la elección de un punto de vista dramático para la presentación de la información, no puede reducirse a un mero acto de superficialidad informativa o sometimiento a las estructuras de mercado por parte de un noticiero. La elección de tal perspectiva, la dramática, y los aspectos de los acontecimientos 
que se invisibilizan como efecto de tal elección, redunda, como lo afirma Hermelin (2008), en el hecho de no dotar a las personas de ciertos conocimientos necesarios para el ejercicio de una democracia participativa -teniendo en cuenta la importancia política que el tema del cambio climático ha venido cobrando en Colombia -, y en el desconocimiento, por parte de la sociedad en general, de las formas de prevención y movilización social con las que se puedan reducir los peligros, en diversos aspectos, de las consecuencias del cambio climático.

Es necesario, no obstante, especificar los grupos sociales entre los que se desarrolla la violencia simbólica que se ha mencionado. Nótese que al usar la noción de Bourdieu de violencia simbólica, se tiene en cuenta también la noción de dominación de Van Dijk, en el sentido del control ejercido por un grupo social, desde los medios de comunicación y los discursos, hasta las estructuras mentales de la instancia receptora.

Para Van Dijk, los Estudios del Discurso podrán definirse más específicamente como críticos si satisfacen uno o varios de los siguientes criterios:

- Las relaciones de dominación se estudian primariamente desde la perspectiva del interés del grupo dominado y a favor de éste.

- Las experiencias (de los miembros) de los grupos dominados se emplean además para evaluar el discurso dominante.

- El estudio puede mostrar que las acciones discursivas del grupo dominante son ilegítimas.

- Pueden formularse alternativas a los discursos dominantes que coinciden con los intereses de los grupos dominados.

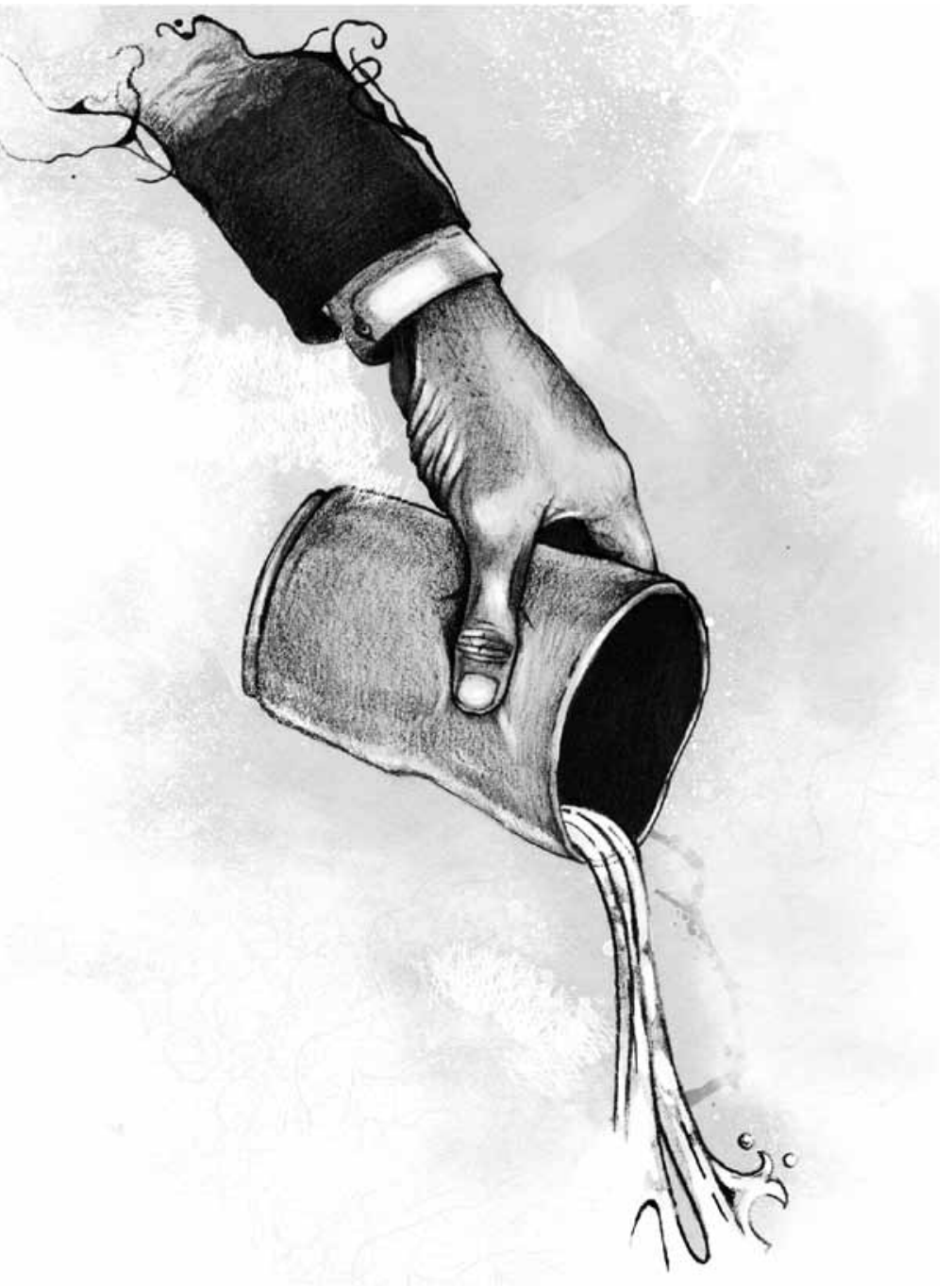

Teniendo en cuenta que el estudio se ocupó esencialmente del discurso y no de sus formas de producción y recepción, los dos primeros criterios quedaron invalidados para el análisis. El cuarto criterio aparecerá más adelante en el apartado ¡Prevención, no sólo información!

Es difícil definir los grupos sociales entre los que se da la relación de dominación, pues aquí no se enfatiza en la instancia receptora ni emisora. No obstante, anteriormente, al hablar de la función de poder del discurso, se precisó el poder simbólico otorgado a los medios por el hecho de ser ellos quienes poseen determinada información. Así, los grupos sociales en conflicto serían aquellos agentes, entidades, instituciones o personas poseedoras de información y aquellos que no la poseen. Para nuestro caso, el grupo dominante sería el telenoticiero RCN. Ahora bien, el grupo dominante posee no sólo una información sino mayores facilidades para la adquisición de tal información, que es de notable importancia social. Tal conocimiento debería ser usado con propósitos 
comunes: han de examinarse en la mayor medida posible todos los aspectos sociales de los hechos que constituirán la información, de modo que los grupos dominados estén en igualdad de condiciones respecto al conocimiento, en este caso, del cambio climático y sus consecuencias naturales y sociales. Como se ha mostrado, la imposición de una perspectiva dramatizante a la información implica una homogeneización de las noticias y un desconocimiento de los aspectos socialmente importantes. Las estrategias de dramatización presentes en el discurso, son acciones discursivas ilegítimas que atentan contra la democracia participativa y la acción social concertada.

\subsection{La relación de los campos}

Como se ha advertido, el tema del cambio climático en los medios de comunicación involucra dos campos de producción cultural, el científico y el periodístico, de modo que todo análisis discursivo acerca del tema habrá de considerar, además del discurso mismo, las relaciones comunicativas entre ambos campos. Digo comunicativas porque en última instancia estas relaciones se definen por el grado de acercamiento que los productores de cada campo tengan entre sí y por las perspectivas desde las cuales la comunicación interpreta la información científica. Las relaciones que puedan establecerse entre ambos terrenos de producción pueden llegar a ser contradictorias y hostiles, considerando que la influencia de las estructuras económicas y políticas en el campo periodístico tienden a extenderse hacia el campo con el que se establece la relación. Como observa Bourdieu, "La influencia del campo periodístico tiende a reforzar en cualquier otro campo a los agentes y las instituciones situados en la proximidad del polo más sometido al efecto del número y del mercado" (Bourdieu, 1997:110). Sin embargo, teniendo en cuenta que los intereses económicos afectan la producción científica relativa al cambio climático, no se puede afirmar que el campo científico es un orden de producción completamente puro cuya autonomía, respecto a las lógicas del mercado, no se ha visto afectada.

La relación entre el campo periodístico, el científico y el social se da en un esquema triangular en el que la comunicación media entre la ciencia y la sociedad, dirigiendo la reformulación destinada para el público de las producciones lingüísticas de los especialistas (Moirand, 2003:2). Ahora bien, los modos en los cuales se relaciona el campo periodístico con el científico están determinados por las dimensiones comunicativas - puntos de vista desde los cuales se construye el discurso - y las dimensiones cognitivas - las representaciones de los tipos de conocimiento y las operaciones cognitivas usadas - implícitas en todo discurso (Moirand, 2003: 3). El campo periodístico interpreta, a partir de determinadas dimensiones comunicativas, determinadas perspectivas, los datos obtenidos en el campo científico. Esta interpretación, este cambio de perspectiva, implica privilegiar ciertos aspectos de la información que tengan mayor relevancia social, en tanto el actor al que se dirige el nuevo discurso es la sociedad. El objeto discursivo en el campo periodístico no ha de ser las descripciones científicas de los fenómenos sino la relación de tales descripciones con aquellos aspectos que en determinado momento pueda afectarla. 


\subsection{La no-comunicación entre campos, la deformación del discurso y las diferencias de perspectiva}

Se encontró en el estudio que las relaciones entre el campo periodístico y el campo de la ciencia se manifiestan en dos instancias, la no-comunicación y la deformación del discurso. La primera se presenta como consecuencia de la importancia que se le otorga a la perspectiva dramática del discurso. La construcción de un discurso desde un punto de vista sensacionalista no requiere del estudio y análisis especializado de los hechos, en tanto los valores que definen el discurso son, si se quiere, universales, pues hacen parte de los ámbitos de experiencia de todo individuo. Así, aunque el discurso sea construido a partir de un fenómeno perteneciente a un campo especializado -la meteorología-, la comunicación entre dicho campo y el periodístico se anula ya que no se requieren las nociones especializadas para la construcción del discurso, basta con que del hecho referido se puedan enumerar las muertes que causa, los accidentes, las pérdidas materiales o sus aspectos grandilocuentes.

Ahora bien, además de esta no-comunicación se da también lo que he llamado la deformación del discurso. Esto es ante todo un efecto de la debilidad comunicativa entre campos. Los datos obtenidos en el campo científico, el discurso científico, suelen ser modificados cuando pasan al campo periodístico. Este trabajo no buscó estudiar en profundidad las razones de tal circunstancia, dicho propósito hubiese implicado un estudio al interior del noticiero que considere, entre otras variables, sus relaciones con el campo económico y sus lógicas particulares de producción discursiva. No obstante, de acuerdo con lo que se ha venido exponiendo, pueden establecerse las siguientes dos explicaciones:

- Las modificaciones del discurso científico no se dan como una consecuencia natural de la diferencia de perspectiva entre ambos campos, sino por el desconocimiento de las nociones y presupuestos implícitos en el discurso científico.

- El discurso producido por el telenoticiero, como se ha enfatizado, es ante todo dramatizante, de ahí que se ignoren la mayor parte de los aspectos científicos de los eventos.

Aunque el campo periodístico no pueda pretender construir discursos científicos pues su terreno es fundamentalmente social, sus diversas relaciones con otros órdenes, la pérdida del rigor con el uso de términos, nociones, conceptos o expresiones, puede llegar a generar un desconocimiento, desde lo social, de las consecuencias o manifestaciones de un fenómeno explicado por la ciencia. Por ejemplo, juzgar las inundaciones de ciertas zonas pobladas del país como mera consecuencia del aumento de precipitaciones, es ignorar que tal aumento es un fenómeno natural y que por tanto siempre han existido zonas con mayor riesgo de inundaciones, de modo que las dificultades derivadas de las inundaciones se deben ante todo a un problema de planeación social. Esto último es ampliado en el apartado ¡Prevención, no sólo información!

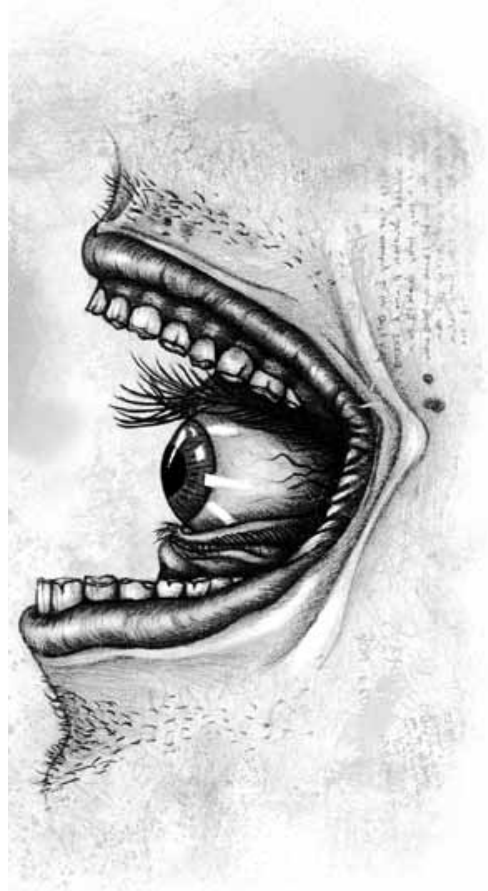


Surge entonces un problema a enfrentar, ¿cómo han de establecerse las relaciones comunicativas entre ambos campos y cuáles son las perspectivas que el campo periodístico ha de privilegiar para la construcción del discurso informativo? Esta cuestión podría llegar a implicar un largo trabajo de discusión teórica. Aquí plantearía desde mi experiencia una solución en la que se privilegian los aspectos discursivos relacionados con las consecuencias sociales del fenómeno del cambio climático. Es claro que el discurso informativo no podría ser enteramente científico, en tanto sería incomprensible para un fragmento significativo de la instancia receptora. Esto no justificaría la carencia de rigor, como ha venido afirmándose. Teniendo en cuenta las iniciativas políticas que han tenido como objeto la disminución de los gases de efecto invernadero, el campo periodístico debería ubicarse en esta perspectiva para incluir la sociedad civil en dichas iniciativas. Los hábitos de consumo excesivo son una de las variables importante en las emisiones de GEI; el uso excesivo de aires acondicionados o de sistemas de calefacción, el uso de aparatos que podrían reemplazarse, como los lavaplatos eléctricos, el uso irresponsable de electrodomésticos, etc., aumentan los niveles de emisión (Lomborg, 2004:44). Otra variable significativa está relacionada con el aumento de los niveles poblacionales en todo el mundo, pues este aumento incrementa necesariamente el consumo y la explotación de recursos.

Así, los medios de comunicación deberían partir de la idea de que el cambio climático no es un asunto causado sólo por las emisiones de GEI de los grandes sistemas industriales, sino también es propiciado por las conductas culturales con las que nos relacionamos con el medio ambiente. Se requeriría, desde el discurso informativo, un fuerte conocimiento de las formas en las cuales nuestros hábitos de consumo afectan el medio ambiente, de modo que sea posible realizar una especie de proyecto comunicativo que tienda a crear conciencia sobre tales hábitos y sus consecuencias. Otra de las perspectivas desde las cuales el discurso informativo debería plantearse es la que se esbozará a continuación.

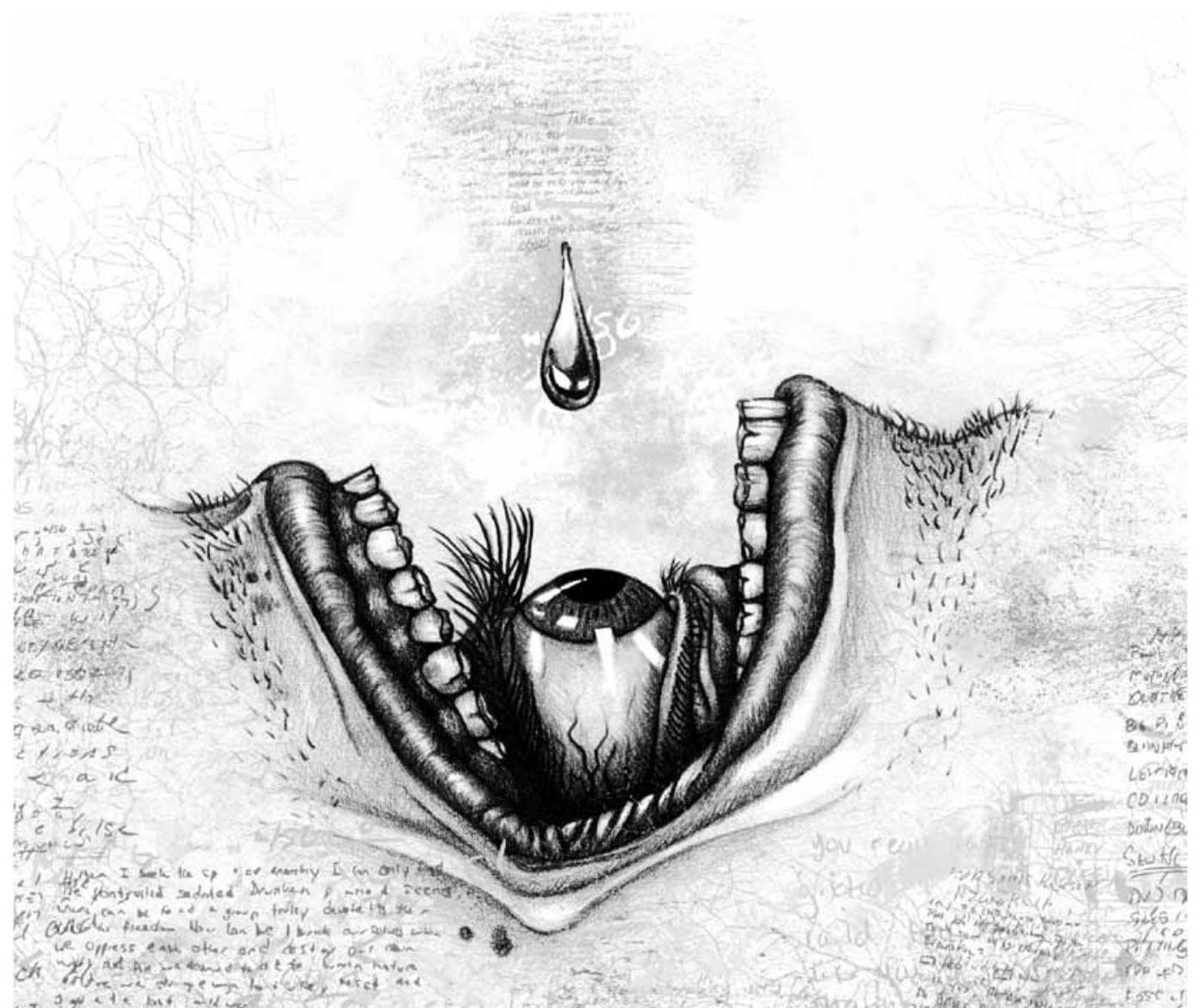




\section{Conclusiones}

Estas conclusiones se presentan en dos partes, la primera concierne a los resultados cuantitativos de la investigación. La segunda parte propone una reflexión en torno a la necesidad de prevención desde los discursos informativos.

El tipo de actor privilegiado en las noticias fue el presentador/narrador, entendido éste como el presentador del noticiero que en cierto momento -cuando el busto parlante es remplazado por la imagen de lo que se relata- se convierte en el narrador encargado de ampliar el discurso. En total, fueron 28 noticias en las que el presentador obró como narrador. En segundo lugar, aparece el narrador en 23 noticias. La voz oficial del gobierno se encontró en 19 noticias, los testimonios de testigos aparecieron en 11 y sólo se recurrió a la voz experta en 4 noticias. Esta primera conclusión, relativa a los actores que tuvieron mayor importancia para el noticiero televisivo (NT), manifiesta la débil relación entre el campo de la ciencia y el NT.

Según la categorización temática elaborada para efectos de este trabajo, los hechos específicos que tuvieron cubrimiento en las noticias estudiadas fueron los siguientes. Relativos a:

- Precipitaciones: 28

- Acciones políticas, sociales y civiles: 18

- Vientos fuertes: 12

- Geología: 8

- Temperatura: 6

- Oceanografía: 3

- Fenómeno clasificado como "extraño fenómeno": 1
Como se ha indicado a lo largo del texto, el tipo de estrategia dominante para la presentación de la noticia, corresponde a formas de construcción discursivas que dramatizan los eventos comentados. Éstas se manifiestan, oralmente, en el uso constante de adjetivos de orden emocional y de cifras exageradas. En el discurso audiovisual, las estrategias dramatizantes son visibles en los tipos de planos usados así como en los objetos filmados, en figuras retóricas como la repetición de planos y en el hecho de privilegiar los audios diegéticos cuando conciernen a expresiones de angustia o dolor.

El tipo de discurso predominante, es ante todo un discurso construido a partir de concepciones dramáticas y emocionales de los hechos que se comentan. Siguiendo a Charaudeau en lo que respecta a la triple mímesis por la cual un hecho del mundo fenoménico pasa a formar parte de un universo discursivo, el potencial propio de los hechos para ser comentados es valorado según la capacidad para generar emociones de miedo, angustia, dolor o alarma en el espectador. Las categorías de percepción de los agentes productores de información establecen como valor mayor el potencial dramático de los acontecimientos.

\section{¡Prevención, no sólo información!}

Al hablar de prevención, es necesario hacer énfasis en el hábito de la inmediatez en la producción de información. Respecto al tema del cambio climático, nos ubicamos una vez más en sus efectos naturales y sociales. Entre los efectos del cambio climático que más han llamado la atención en los medios colombianos está el aumento de precipitaciones y sus consecuencias. Como se ha mostrado, la construcción del discurso informativo es ante todo coyuntural, obedece a las necesidades de inmediatez y espectacularidad. Ya se insinuó que construir el discurso desde estas consideraciones invisibiliza ciertos aspectos de los fenómenos de mayor importancia social. En el ejemplo de las precipitaciones, entre los aspectos verdaderamente importantes que oculta el discurso sensacionalista está el crecimiento de los niveles poblacionales de 
ciertas regiones colombianas que se manifiesta en la aparición de conglomerados sociales en lugares de alto riesgo, como las riveras de los ríos y en las montañas. Este aspecto, bastante complejo, implica el orden político, económico y social a la vez. Elaborar una información desde estas perspectivas es darle al problema las dimensiones que verdaderamente lo componen. Las precipitaciones en Colombia llegan a ser catástrofes naturales de altos costos materiales y humanos, pues vienen a ser un problema que se suma a circunstancias de planeación política y de orden social. Ante el fenómeno de las inundaciones cabría preguntarse (pregunta que no se hacen los medios), ¿quién permite la construcción o la aglomeración de personas en zonas de alto riesgo? ¿Están los sistemas de alcantarillado en las condiciones adecuadas para enfrentar los efectos del aumento de lluvias? ¿Cuáles son las normas de construcción de viviendas en zonas cercanas a ríos? Este tipo de interrogantes hacen que la información y el problema se contextualicen política, económica y socialmente, así como también exigen que el discurso no sea construido a partir de los desastres presentados, sino desde la prevención de éstos.

Sin embargo, hay una circunstancia a resaltar de las noticias estudiadas en este trabajo: la relativa a la campaña de información que el noticiero llevó a cabo acerca de las obras de mitigación de la nueva temporada invernal en Colombia. Esta campaña buscaba informar a la vez que denunciar el estado de las obras de mitigación correspondientes a cada departamento, ante la eventual proximidad de la nueva temporada de lluvias pronosticada por el Ideam.

Aunque la campaña inició poco tiempo antes de la ola invernal, es rescatable la iniciativa de revisar el estado de las obras y cuestionar sus avances parciales. Esta actividad informativa puede ser considerada como una primera tentativa de abordar las consecuencias del cambio climático desde una perspectiva preventiva. Así, es necesario que los medios desarrollen estrategias comunicativas que busquen la prevención de los desastres, estrategias dirigidas en dos sentidos: a nivel gubernamental, de modo que se transite desde las políticas de emergencia hacia políticas de largo plazo, manejo de suelos, viviendas, asentamientos humanos, desarrollo social; y a nivel social, de modo que pueda pasarse de la reacción espontánea hacia el fomento de la organización social tanto para la emergencia como para la prevención. Se trata ante todo de estrategias comunicativas dirigidas a modificar una actitud cultural respecto a los desastres naturales.

Como puede percibirse, existen dos circunstancias que han sido de importancia notoria para el análisis: han servido como las ideas fundamentales a partir de las cuales se desarrolló el estudio y se hizo la crítica. Tales circunstancias son la relación comunicación cambio climático y la necesidad de la construcción de discursos que propendan en mayor medida a la prevención. El discurso dramático, aquel que prioriza una perspectiva emocional en los acontecimientos mediáticos, debe ser estudiado minuciosamente en todos los medios en que aparezca, no sólo para determinar las formas en las cuales se efectúa la coerción política y económica, sino para desentrañar los mecanismos por los cuales se ejercen diversos modos de dominación entre grupos y se violenta simbólicamente ciertos órdenes de la sociedad. Al referirnos a los medios sensacionalistas y sus discursos, no hablamos de una actividad comunicativa inocua e intelectualmente despreciable que sirve para el entretenimiento de las clases populares; se habla de formas institucionalizadas de violencia, de negación de derechos, de lesiones a la democracia, de negación de la ética profesional. Como ya ha afirmado Hermelin, juzgar que el público es pasivo y justificar con eso el sensacionalismo mediático, es una generalización falsa que encubre la responsabilidad social de los medios (Hermelin, 2008: 68).

El tema del cambio climático ha tenido para el campo periodístico, desde mediados del siglo pasado, las particulares complejidades derivadas de la incertidumbre científica que ha acompañado su desarrollo científico. En el presente, muchos de los aspectos del cambio climático, sus causas y consecuencias son una certidumbre y otros aún están por resolverse. Sin embargo, los descubrimientos científicos que ayudan a conocer mejor el fenómeno y sus efectos parece que pasan desapercibidos para 
los medios en Colombia. La relación entre la ciencia y la sociedad, mediada por la comunicación como interpretadora y constructora de sentidos, todavía es débil. Las consecuencias sociales del cambio climático y las formas de prevención y movilización no son parte de las agendas mediáticas y apenas sí de los estudios teóricos (Hermelin, 2008:71). Es necesario pues fortalecer esa relación, propósito que implica el inicio de una preocupación sistemática desde la academia, los medios y en general, del Estado, por el tema. Como se ha insinuado a lo largo del texto, muchas de las dificultades que las consecuencias del cambio climático han originado en Colombia podrían mitigarse y evitarse con un conocimiento mayor del tema, conocimiento que ahora se tiene pero que no alcanza al campo periodístico ni a la sociedad.

Es urgente la necesidad de la construcción, desde la academia y las diversas posibilidades mediáticas, de discursos que manifiesten un conocimiento profundo del tema y de sus consecuencias, discursos formulados a partir de la indagación científica que busquen formar a sus públicos en los modos de relacionarlos mejor con el ambiente, que contextualicen y den al problema sus dimensiones sociales, políticas y económicas. Las consecuencias del cambio climático y los problemas en que derivan, complejizan más ciertas circunstancias sociales relativas a la pobreza, el desplazamiento y la desigualdad social. Es necesaria la acción concertada, en la que la instancia comunicativa cumpla un significativo papel, para enfrentar adecuadamente el fenómeno.

\section{Referencias}

Bourdieu, Pierre (1997). Sobre la televisión. Barcelona. Editorial Anagrama.

(2006). La lógica de los campos. Recuperado en agosto de 2011 http:/ / pierre-bourdieu.blogspot.com/2006/07/la-lgica-de-los-camposentrevista.html

Charaudeau, Patrick (2003). El discurso de la información. La construcción del espejo social. España: Gedisa.

Hermelin Bravo, Daniel (2008). Comunicación, medio ambiente y cambio climático: retos para Colombia. Medellín: CORANTIOQUIA.

(2007). Los desastres naturales y los medios en Colombia: ¿Información para la prevención? En "Gestión y Ambiente”Vol 10. N². Agosto 2007.

Lomborg, Bjorn (2008). En frío, la guía del ecologista escéptico. España: Espasa Calpe, S.A.

Van Dijk, Teun A (1990). La Noticia como Discurso. Barcelona: Ediciones Paidós Ibérica, S.A. (2009) Discurso y poder. Barcelona: Editorial Gedisa, S.A.

Recibido: abril 30 / Aprobado: junio 12 de 2012 